\title{
The value of a post-polio syndrome self-management programme
}

\author{
Alexandra Curtis ${ }^{1 \#}$, Jeong Su Lee ${ }^{1 \#}$, Georgios Kaltsakas ${ }^{1,2}$, Vivian Auyeung ${ }^{2}$, Simon Shaw ${ }^{1}$, \\ Nicholas Hart ${ }^{1,2}$, Joerg Steier ${ }^{1,2}$ \\ ${ }^{1}$ Guy's and St Thomas' NHS Foundation Trust, London, UK; ${ }^{2}$ Faculty of Life Sciences and Medicine, King's College, London, UK \\ Contributions: (I) Conception and design: A Curtis, JS Lee, N Hart, J Steier, V Auyeung; (II) Administrative support: A Curtis, JS Lee, N Hart, J \\ Steier; (III) Provision of study materials or patients: A Curtis, JS Lee, J Steier, S Shaw, V Auyeung; (IV) Collection and assembly of data: A Curtis, \\ JS Lee; (V) Data analysis and interpretation: A Curtis, JS Lee, J Steier, V Auyeung, G Kaltsakas; (VI) Manuscript writing: All authors; (VII) Final \\ approval of manuscript: All authors. \\ "These authors contributed equally to this work. \\ Correspondence to: Ms. Alexandra Curtis, MRes, BSc. Guy's and St Thomas' NHS Foundation Trust, Lane Fox Unit, Westminster Bridge Road, \\ London SE1 7EH, UK. Email: alexandra.curtis@gstt.nhs.uk.
}

Background: Post-polio syndrome is characterised by symptoms of fatigue, pain and new-onset neuromuscular weakness, and emerges decades after the initial poliovirus infection. We sought to evaluate the only post-polio syndrome specific self-management programme in the United Kingdom.

Methods: This was a retrospective study of patients who had completed a residential self-management programme led by a multi-disciplinary clinical team. Following a confirmed diagnosis of post-polio syndrome by rehabilitation and neurology specialists, patients were offered to participate in the programme. Although group-based, patients also received individually tailored support on physical exercise and fatigue management. Physical effects, physical function, psychosocial well-being measures were assessed at baseline and 6 months follow-up. Knowledge was tested at baseline and immediately following the programme. Statistical comparisons were made using paired t-test and Wilcoxon signed rank test according to the data distribution.

Results: Over a period of 17 years, 214 participants (median age 61.3 years old, 63\% female) attended 31 programmes. At 6 months the following post-polio syndrome specific symptoms improved significantly: fatigue, as measured by the Multidimensional Assessment of Fatigue scale [37.6 (7.1) vs. 34.2 (9.3), $\mathrm{P}=0.005$ ]; and pain [15.0 (6.1) vs. 13.1 (6.7), $\mathrm{P}=0.001]$, atrophy [10.0 (8.0-12.0) vs. 9.0 (7.0-11.0), $\mathrm{P}=0.002]$ and bulbar symptoms [3.0 (1.0-5.0) vs. $2.0(0-4.0), \mathrm{P}=0.003]$ as measured by the Index of Post-polio Sequelae scale. Knowledge related to post-polio syndrome also significantly increased [14.0 (11.0-16.0) vs. 17.0 (16.0-19.0), P=0.001]. Participants were able to walk at a faster speed over 10 meters $[0.77(0.59-1.00)$ vs. $0.83(0.67-1.10) \mathrm{m} / \mathrm{s}$, $\mathrm{P}=0.003]$ and walked longer distances during the 2-minute walk test [76.9 (31.7) vs. 82.0 (38.4) $\mathrm{m}, \mathrm{P}=0.029]$. Depression and anxiety scores did not change over time [PHQ-9, 2.0 (0.3-10.8) vs. 2.0 (0.3-6.8), $\mathrm{P}=0.450$; GAD-7, $2.0(0-7.0)$ vs. $1.0(0-3.0), \mathrm{P}=0.460]$ nor was there change in self-reported quality of life $\{60$ [50-70] vs. 60 [55-70], $\mathrm{P}=0.200\}$.

Conclusions: This study suggests that a post-polio syndrome self-management programme led to improvement in symptoms, knowledge and walking speed, but not quality of life. Anxiety and depression scores remained low.

Keywords: Rehabilitation; post-polio syndrome (PPS); fatigue; quality of life (QoL)

Submitted Jun 22, 2020. Accepted for publication Sep 03, 2020.

doi: 10.21037/jtd-cus-2020-009

View this article at: http://dx.doi.org/10.21037/jtd-cus-2020-009 


\section{Introduction}

Comparisons have been drawn between the polio epidemics in Europe and USA that spiked seasonally in the first half of the 20th century and the need for a vaccine and the social responses during the COVID-19 pandemic (1). Post-polio syndrome (PPS) is a progressive neurological condition characterised by mild to extreme symptoms of fatigue, new muscular weakness and pain that emerges decades after the acute poliomyelitis viral infection (2). Symptoms of PPS can also include respiratory muscle weakness and swallowing insufficiencies. Combined with pre-existing neurological and orthopaedic impairments as a consequence of the original polio, symptom burden can be high (3). The pathogenesis of PPS is still not fully understood and it has taken many years of campaigning to be widely recognised as a distinct condition within the medical community (4). It is estimated that more than $80 \%$ of 120,000 polio survivors are living with PPS in the UK (5).

Although there are limited data examining the longterm outcomes of the COVID-19 outbreak there are some similarities between PPS symptoms and other viral pandemics. Symptoms such as fatigue, pain and neuromuscular weakness suggest we should be generally cognizant about the potential chronic effects of viral infections (6-8).

Self-management groups for chronic conditions have been established in many settings to guide patients when treating chronic pain, arthritis, chronic obstructive pulmonary disease and other disease. Benefits have been shown to include positive effects on quality of life (QoL) and function $(9,10)$. Pulmonary rehabilitation includes many educational aspects of self-management and has been proven to have some of the highest evidence of efficacy for interventions of long-term conditions (11).

In order to manage PPS better, a multi-disciplinary selfmanagement course was established 17 years ago at a South London hospital. A pilot study of 27 participants completing the self-management course was published in 2008 (12) which suggested positive effect on depression levels, chronic fatigue, shuttle walk distance and perceived exertion. Larsson Lund et al. (13) suggested a multidisciplinary based programme could bring positive change through reducing the burden of illness for those attending a PPS programme in Sweden. However, globally there remains little evidence to demonstrate what specific benefits a self-management programme delivers for PPS sufferers.

It was hypothesised that a structured self-management programme for PPS could improve outcomes for long-term survivors of the condition. An evaluation of this dataset with 6-month follow-up data was undertaken to inform the benefit of such a programme for PPS patients in the aftermath of severe viral illness due to a pandemic.

We present the following article in accordance with the STROBE checklist (available at http://dx.doi.org/10.21037/ jtd-cus-2020-009).

\section{Methods}

This study was conducted in accordance with the Declaration of Helsinki (as revised in 2013). This study was registered and approved as a service evaluation with the institutional clinical governance review board (reference number: GSTT-9729) and did not require ethical approval. Patients who were referred to the PPS service at the Lane Fox Unit, Guy's \& St Thomas' NHS Foundation Trust, London, UK were offered and approached to participate in the self-management programme. Patients had to have a confirmed diagnosis of PPS following specialist review with rehabilitation and neurologist specialists. Exclusion criteria for the course included not being able to attend a residential programme, unable to actively participate in any of the exercise sessions or lacking understanding of spoken English. Each participant provided verbal consent for the programme participation and completing outcome measures.

\section{Self-management programme}

This residential course initially comprised of nine, or more recently six days of practical and classroom-based content. It was facilitated by an experienced occupational therapist and physiotherapist and individual sessions were delivered by other clinicians such as respiratory and rehabilitation specialists, neurologists, dieticians, psychologists and psychiatrists with connections to the polio population via the same London hospital. The course has evolved and content has been amended over time. However, a core curriculum has addressed the same key themes throughout the assessment period:

* Fatigue management;

* Individual tailored exercise programmes;

* Falls management;

* Mood and anxiety in the context of a long-term condition;

* Cognitive behaviour therapy to facilitate change;

* Sleep and respiratory considerations in PPS; 
Table 1 Description of the outcome measures used to evaluate PPS symptoms. All are scores except, the 10-meter walk test was measured in meters per second, the 2-minute walk test was measured in meters and 30sCST measured in repetitions

\begin{tabular}{|c|c|c|}
\hline Outcome measure & Description and scoring & Date commenced \\
\hline \multicolumn{3}{|l|}{ Physical effects related to PPS } \\
\hline IPPS & $\begin{array}{l}\text { Likert scale, severity of PPS specific symptoms. Twelve items clustered into } 4 \\
\text { constructs: pain } 0-30 \text { points, atrophy } 0-15 \text { points, bulbar function } 0-10 \text { points, } \\
\text { temperature control } 0-5 \text { points }\end{array}$ & Sep 2006 \\
\hline MAF & Fatigue rated over the last week, 16 items, $0-50$ points & Aug 2016 \\
\hline PPS Knowledge test ${ }^{\dagger}$ & PPS knowledge 0-22 points & Oct 2003 \\
\hline \multicolumn{3}{|l|}{ Well-being } \\
\hline QoL visual analogue scale & Quality of life scale with no anchors $0-100$ points & Jan 2003 \\
\hline COPM & $\begin{array}{l}\text { Rating performance (COPM-p) and satisfaction (COPM-s) with activities } \\
\text { self-identified as important, both 0-50 points }\end{array}$ & May 2005 \\
\hline GAD-7 & Anxiety: none $0-5$, mild $6-10$, severe $16-21$ points & Sep 2015 \\
\hline \multicolumn{3}{|l|}{ Physical function } \\
\hline 10-meter walk test ${ }^{\ddagger}$ & Walk speed in meters per second $(\mathrm{m} / \mathrm{s})$ & Jan 2003 \\
\hline 2-minute walk test ${ }^{\ddagger}$ & Distance in meters (m) & Aug 2010 \\
\hline 30sCST ${ }^{\ddagger}$ (Modified) & $\begin{array}{l}\text { Number of repetitions over } 30 \text { seconds, (allowing arm use and from a comfortable } \\
\text { height) }\end{array}$ & Nov 2016 \\
\hline
\end{tabular}

${ }^{\dagger}$, outcome measures were retested at 6 months, except the PPS knowledge test which was retested on the final day of the PPS course; ‡, outcomes measured by clinicians, all others are self-reported. PPS, post-polio syndrome; IPPS, The Index of Post-polio Sequelae; MAF, Multidimensional Assessment of Fatigue; QoL, quality of life; COPM, Canadian Occupational Performance Measure; PHQ-9, Patient Health Questionnaire; GAD-7, General Anxiety Disorder; 30sCST, 30-second Chair Stand test.

* Diet recommendations;

* Individual goal setting.

\section{Study design}

This retrospective cohort study examined clinical outcomes measured on the first day of the structured PPS selfmanagement programme, with repeat measurements taken 6 months later. Incomplete datasets due to not attending for the 6-month review or loss-to-follow-up were excluded from the analysis.

\section{Outcome parameters}

A total of ten different outcome measures, assessing the impact of the known symptoms of PPS, were analysed. The primary outcomes measured self-reported physical effects related to PPS [The Index of Post-polio Sequelae (IPPS) (14) and Multidimensional Assessment of Fatigue (MAF) (15)] and understanding of the condition (PPS knowledge test). The secondary outcomes quantified aspects of wellbeing [QoL (16), Canadian Occupational Performance Measure (COPM) (17), General Anxiety Disorder (GAD-7) (18), Patient Health Questionnaire (PHQ-9) (19)] and physical function [speed using the 10 -meter walk test (20), distance using the 2-minute walk test (21) and 30-second Chair Stand test (30sCST) (22)]. All outcomes were assessed at baseline and repeated at 6-month follow-up except the PPS knowledge test which was repeated on the last day of the programme. The number of results for each outcome measure varied due to exclusion of incomplete data sets and the timeframes outcome measures were introduced in the evolution of the course. Outcome measurements are summarised in Table 1. 
Table 2 Demographic data of patients attending the PPS self-management courses

\begin{tabular}{lc}
\hline Variables & Value \\
\hline Gender $(\mathrm{n}=214), \mathrm{n}(\%)$ & $79(36.9)$ \\
Male & $135(63.1)$ \\
Female & $61.3(8.4)[34-85]$ \\
Age $(\mathrm{n}=214)$, mean (SD) [range] (years) & $134(62.6)$ \\
$<65$ years old, $\mathrm{n}(\%)$ & $80(37.4)$ \\
$\geq 65$ years old, $\mathrm{n}(\%)$ & $4(2.1)$ \\
Decade of contracting acute polio ( $\mathrm{n}=195), \mathrm{n}(\%)$ \\
$1930-1939$ & $51(26.2)$ \\
$1940-1949$ & $112(57.4)$ \\
$1950-1959$ & $19(9.7)$ \\
$1960-1969$ & $5(2.6)$ \\
$1970-1979$ & $4(2.1)$ \\
$1980-1989$ &
\end{tabular}

Geographical area where acute polio was contracted $(n=197), n$ (\%)

$\begin{array}{lc}\text { UK } & 163(82.7) \\ \text { Africa } & 11(5.6) \\ \text { Asia } & 8(4.1) \\ \text { Middle East } & 7(3.6) \\ \text { Europe } & 4(2.0) \\ \text { South America } & 3(1.5) \\ \text { Canada } & 1(0.5)\end{array}$

Area of the body with residual weakness following acute polio $(\mathrm{n}=198), \mathrm{n}(\%)$

$\begin{array}{lc}\text { Unilateral LL } & 80(40.4) \\ \text { Bilateral LL } & 51(25.8) \\ \text { UL and LL } & 39(19.7) \\ \text { Spine/spine and limbs } & 21(10.6) \\ \text { UL unilateral } & 4(2.0) \\ \text { UL bilateral } & 2(1.0) \\ \text { None } & 1(0.5)\end{array}$

PPS, post-polio syndrome; SD, standard deviation; UK, United Kingdom; LL, lower limb; UL, upper limb.

\section{Statistical analysis}

Statistical analyses were performed using IBM SPSS version 25 (released 2017, IBM Corp., Armonk, NY, USA). The Shapiro-Wilk test of normality and normal Q-Q Plot of difference were used to check data distribution. The demographic characteristics are reported as percentages for categorical data and mean (standard deviation, SD) following testing for normality. The total range was reported for continuous variables. Parametric data were analysed using the Shapiro-Wilk test and a paired-samples t-test was used, while the Wilcoxon signed rank test was used with non-parametric data. A P value of 0.05 or less was considered significant.

\section{Results}

Between 13th January 2003 and 1st March 2019, 214 individual patients attended the PPS self-management programme over a total of 31 courses. The group size ranged between 3-11 individuals with a mean of 7.0 (1.9) participants per group. The majority attending the programme contracted polio in the 1950's but a smaller number had acute polio later than 1969 . When they attended the programme 134 (62.6\%) participants were younger than 65 years old. Most frequently the UK was the geographical area where the polio infection occurred but other areas were represented throughout the programmes. The most common residual effect following polio were in the lower limbs. Participant demographics are presented in Table 2.

\section{Physical effects related to PPS}

There were significant changes at 6 months in the outcomes measuring PPS symptoms. Within the IPPS, 3 of 4 constructs improved, pain [15.0 (6.1) vs. 13.1 (6.7), $\mathrm{P}=0.001]$, atrophy $[10.0(8.0-12.0)$ vs. $9.0(7.0-11.0)$, $\mathrm{P}=0.002]$ and bulbar symptoms $[3.0(1.0-5.0)$ vs. $2.0(0-4.0)$, $\mathrm{P}=0.003]$. There was no significant change using the IPPS to rate temperature control [3.0 (2.0-4.0) to 4.0 (2.0-4.0), $\mathrm{P}=0.900]$. In addition, the MAF showed a significant reduction in fatigue levels [37.6 (7.1) vs. 34.2 (9.3), $\mathrm{P}=0.005$ ] at follow-up (Table 3). 
Table 3 Measures of PPS symptoms, physical function, well-being and PPS knowledge at baseline and 6-month follow-up

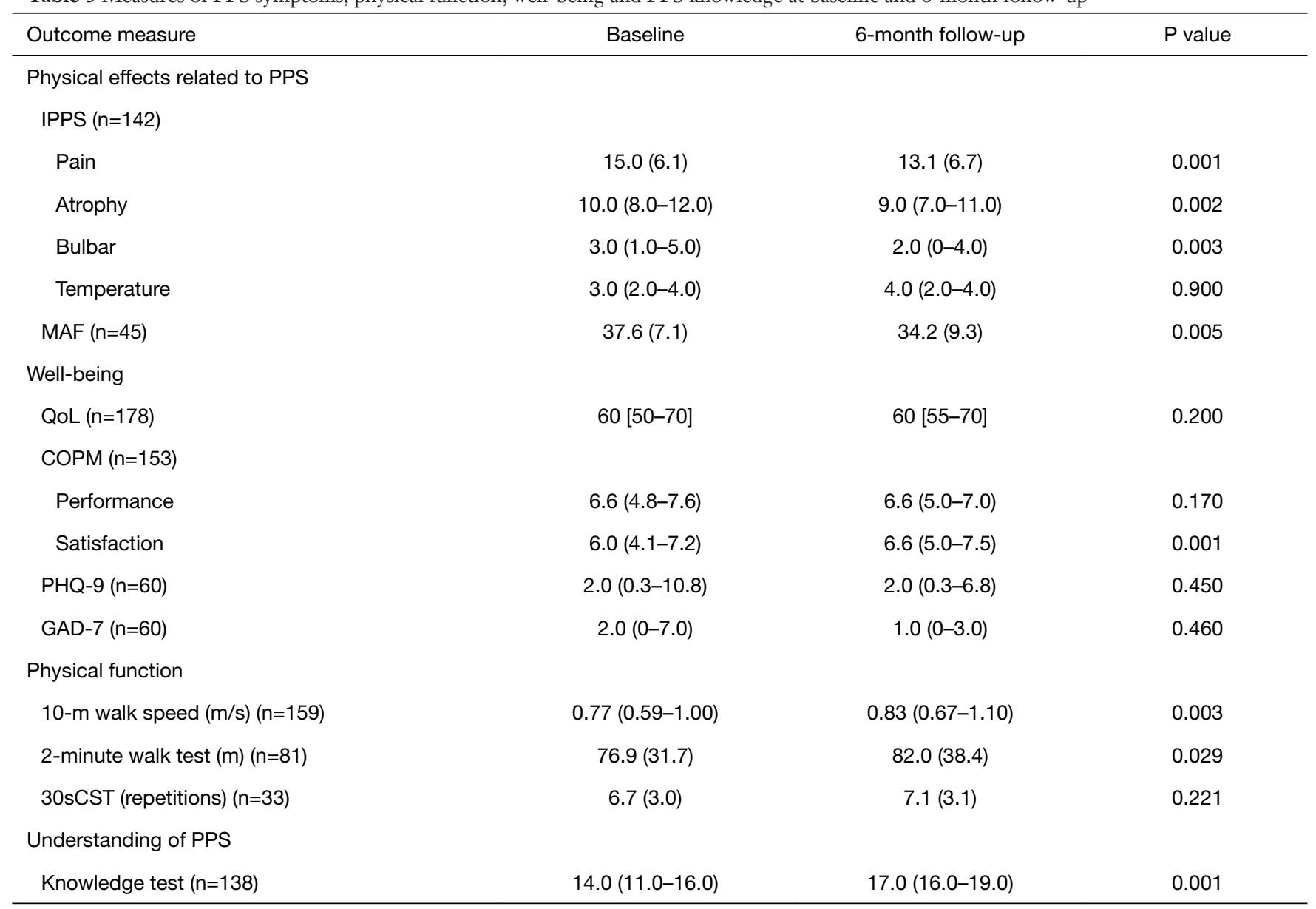

IPPS, The Index of Post-polio Sequelae; MAF, Multidimensional Assessment of Fatigue; QoL, quality of life; COPM, Canadian Occupational Performance Measure; PHQ-9, Patient Health Questionnaire; GAD-7, General Anxiety Disorder; 30sCST, 30-second Chair Stand test.

\section{Well-being}

There was no change in the perceived QoL [60 (50-70) vs. 60 (55-70), $\mathrm{P}=0.200$ ] at follow-up, but significant improvement with the COPM in reported satisfaction with performance of activities that individual participants had identified as meaningful to them [COPM-s 6.0 (4.1-7.2) vs. 6.6 (5.0-7.5), $\mathrm{P}=0.001]$, although their rating of the performance of the same activities had not changed [COPM-p 6.6 (4.8-7.6) vs. 6.6 (5.0-7.0), $\mathrm{P}=0.170]$. The depression and anxiety scores were not different between baseline and follow-up [PHQ-9, $2.0(0.3-10.8)$ vs. 2.0 (0.3-6.8), $\mathrm{P}=0.450$; GAD-7, $2.0(0-7.0)$ vs. $1.0(0-3.0), \mathrm{P}=0.460]$ (Table 3).

\section{Physical function}

Participants in the programme were able to walk at a faster speed over 10 meters [0.77 (0.59-1.00) vs. $0.83(0.67-1.10) \mathrm{m} / \mathrm{s}$, $\mathrm{P}=0.003]$, they could also walk for a longer distance [2-minute walk test, 76.9 (31.7) vs. 82.0 (38.4) m, $\mathrm{P}=0.029$ ] (Table 3).

\section{Understanding of PPS}

The participants' recall of knowledge of PPS showed a significant improvement [14.0 (11.0-16.0) vs. 17.0 (16.019.0), $\mathrm{P}=0.001$ ] (Table 3).

\section{Discussion}

A tailored self-management programme for PPS can significantly improve chronic symptoms, wellbeing, physical function and the understanding of the condition. 
These results are sustained over a period of 6 months. Fatigue, pain, atrophy and bulbar function frequently cause problems in PPS, and all responded well to the intervention. Although the satisfaction with performance score improved as well, this was less markedly beneficial. Most relevant, however, physical function improved, an effect typically observed following evidence-based rehabilitation classes in chronic conditions.

\section{Clinical significance}

Both peripheral fatigue based on a deterioration of performance such as a sustained muscle contraction or a more central fatigue such as sustained attention or whole body activity seem to be a feature of PPS and is reported as one of the most debilitating symptoms (23). At followup, fatigue was notably reduced, and it has to be noted that, generally, PPS-related fatigue does not improve over time without intervention (24); equipping individuals to deal with fatigue is one of the primary aims of the course.

Without a proven pharmacological treatment $(25,26)$ the course addresses PPS fatigue through pacing techniques, knowledge of early signs of fatigue and exercise as well as addressing acceptance of individual limitations.

The sample size was relatively small for the use of the MAF, but the change of 3.4 points was clinically relevant, as a range of 1.4-5.4 points suggests the clinically relevant difference for fatigue reduction (27). However, it remains difficult to describe and quantify fatigue despite it being a common feature of many neurological conditions (28). It should be mentioned that there is a high prevalence of fatigue following acute viral infections, as was also reported in the acute COVID-19 infection (29) and SARS (7), including sleep disturbances similar to that reported within chronic fatigue syndrome.

\section{Symptoms}

This study also showed that there were changes in the IPPS sub-categories of atrophy, pain and bulbar function. It would seem unlikely that atrophy could be changed but this domain also includes questions related to weakness and fatigue. Therefore, an improvement here reflects the positive reduction in the MAF results. It is understood that successful pain management can be partly achieved by changing pain perception (30) and the course is directed towards explanation of the experience of pain as a multidimensional perception, not in terms of damage but in terms of guiding mastery of the symptom. Changes in pain perception could also be attributed to changes in exercise habits, encouraging regular sub-maximal exercise being another aim of the course. Furthermore, the bulbar dysfunction domain incudes questions regarding both bulbar issues and also breathing. General information on both topics is provided, although individual issues may not be addressed through the course. We interpret this improvement in the IPPS bulbar score as the participants having a better understanding of symptoms and seeking specific help or being less concerned having received general information. Finally, unlike the three other domains the IPPS showed no changes in reported temperature control and this remains a symptom which is very difficult to address, $74 \%$ of responders in a large Norwegian study reported issues with the cold (31).

\section{Well-being}

While the symptoms of PPS improved this did not lead to an improvement in the reported performance of activities participants had self-identified as meaningful (COPM-p) but they were significantly more satisfied with the performance of those same activities (COPM-s). Over 6 months, neither the COPM-p nor COPM-s met the minimally clinical important difference (MCID) of a change of 2 points (17). However, it is worth noting while there was no clinical improvement there was also no further decline from baseline, which in itself could be viewed as positive in a progressive condition even if it has only been shown in the short term.

The QoL scale showed no change over the 6-month period, this is despite changes in other domains contributing to quality of life, such as fatigue. Although there are various possible explanations, the Cochrane review of lay-led selfmanagement programmes for long term conditions similarly found that QoL generally did not improve (32).

\section{Mood}

The original pilot study (12) reported a high incidence of anxiety $(33 \%)$ and a moderate incidence of clinical depression (11\%) amongst the PPS cohort. However, our data showed a very low incidence of either anxiety or depression. The median GAD-7 score of $2.0(0-7.0)$ at baseline dropped to $1.0(0-3.0)$ points at follow-up. Using the PHQ-9 a score of 5-9 is suggestive of only mild depression (19) the median of 2.0 at baseline $(0.3-10.8)$ 
and follow-up (0.3-6.8) did not change and would suggest depression was not prevalent at either time point. This result might indicate that there was an element of selfselection by those seeking help and also screening by the course organizers. The participant's activation, defined as the extent that patients have the knowledge, skills, and confidence, to use self-management tools (33) was not formally assessed before joining or on completion of the course, but the organizers did subjectively screen all participants. Appearing amenable to change was part of the inclusion criteria while clinical suggestions of depression would signal a referral for assessment of symptoms prior to attendance on the course being offered.

\section{Physical function}

Unsurprisingly, given the muscle weakness and biomechanical changes commonly seen in survivors of polio, walk speed at both baseline (median $0.77 \mathrm{~m} / \mathrm{s}$ ) and follow-up (median $0.83 \mathrm{~m} / \mathrm{s}$ ) was much lower than the age expected norm; a comfortable walking pace for men and women in their 60's has been found to be 1.36 and $1.30 \mathrm{~m} / \mathrm{s}$, respectively (21). However, the increase in speed was significant and also indicated a small but meaningful change based on an accepted MCID of $0.05 \mathrm{~m} / \mathrm{s}$ (20). Walk speed is important not only because of its clear links to function but also due to its predictive association with falls and health status $(34,35)$. Changes to physical function, such as walking, are frequently what patients first report at the point of seeking medical assistance for PPS $(31,36)$. Additionally, we also used the recommended measurement of distance over time with a 2 -minute walk test. This gives an additional indication of functional capacity because of the impact of fatigue. However, while a small statistically significant increase was seen at followup $(\mathrm{P}=0.029)$, the 5.1 -meter difference falls well short of the MCID for a PPS population of 22.9 meters (36). The 30 sCST test assesses the complex interaction of momentum and stabilisation required to change from the seated to a standing vertical position (37). A repeated sit-to-stand also requires an element of endurance. No difference was found between mean repetition and, again unsurprisingly, given the physical effects of polio the number of repetitions was lower than the reported age related norm of 11-16 over 30 seconds (22). It could be hypothesised that the combination of damaged motor units, reduced endurance and altered movement patterns seen in PPS presents too high a load for individuals to impact on their 30sCST outcomes.

\section{Knowledge}

To the best of our knowledge, this is the only UK programme that focuses solely on the long-term effects of the polio virus. However, the structure of the course is adopted from other long-term self-management programmes where there is emphasis on promoting knowledge of the condition (38). We found a significant improvement of post-polio knowledge, measured through the locally devised knowledge test. This is not a validated tool and retention of that knowledge was not retested at the 6-month follow-up.

\section{Study limitations}

There are a number of limitations impacting on the interpretation of our data. Firstly, the data was collected routinely over 17 years for clinical purposes rather than for the purposes of research. Therefore, data collection was not as robust and complete or systematic as in clinical trials. A small proportion of historical demographic data (8\%) regarding specific year or geographic location of contracting acute polio or the polio residual effects were no longer available or were unknown. We purposefully only included data that were complete at baseline and follow-up which limited the available data sets but might have also skewed some of the overall results. Data was incomplete either because patients did not complete the follow-up or because data from either the baseline or follow-up was not recorded. In order to explore the patterns of missingness, comparisons were made in terms of baseline demographics, age and gender between those with complete paired data and therefore included in the analysis and those with missing data and excluded. This can be seen in the Supplementary information. The results showed the participants whose COPM were included in the study were younger than those whose COPM was missing but there were no other significant differences in terms of gender or age between the two groups. Therefore, it could be suggested while there was missing data this was unlikely to have invalidated the overall results.

Another limitation was the lack of control group and we cannot account for other confounders or suggest the changes seen are correlated to attending the course. The course participants were selected based on the course criteria and self-selection by being able to attend is a potential confounder, although one that similarly applies to other standardised rehabilitation programmes. The use 
of the QoL without anchors used in this programme might not have been sensitive enough in the PPS population; although QoL is multi-dimensional, some polio relevant themes, namely issues with environmental accessibility and health professional's attitudes (39), are beyond the scope of a discreet healthcare intervention, therefore potentially limiting the impact of the course on this domain. Despite these limitations, the authors believe that the dataset suggests the positive value for those who attended the PPS self-management programme. Qualitative feedback of participant's experiences has not been examined here but may further add value and is being analysed separately.

\section{Conclusions}

A self-management programme for PPS can improve fatigue, the severity to which pain, atrophy and bulbar function issues are experienced and the overall knowledge of PPS, as well as physical function over a 6-month period. Despite some limitations the study results are important to a wider audience given the difficulties in collecting systematic data in this cohort and the relatively sparse evidence for the current approach to PPS management. Experiences from PPS management might prove valuable at a time when a new viral pandemic requires us to design future rehabilitation and self-management programmes for many more survivors of a devastating viral condition.

\section{Acknowledgments}

The views expressed are those of the authors and not necessarily those of the NHS, the NIHR or the Department of Health.

Funding: None.

\section{Footnote}

Provenance and Peer Review: This article was commissioned by the Guest Editor (Joerg Steier) for the series " 5 " Clinical Update Sleep" published in Fournal of Thoracic Disease. The article was sent for external peer review.

Reporting Checklist: The authors have completed the STROBE checklist. Available at http://dx.doi.org/10.21037/ jtd-cus-2020-009

Data Sharing Statement: Available at http://dx.doi. org/10.21037/jtd-cus-2020-009
Conflicts of Interest: All authors have completed the ICMJE uniform disclosure form (available at http://dx.doi. org/10.21037/jtd-cus-2020-009). The series " $5^{\text {th }}$ Clinical Update Sleep" was commissioned by the editorial office without any funding or sponsorship. JS served as the unpaid Guest Editor of the series and serves as an unpaid editorial board member of Fournal of Thoracic Disease. JS's contributions were partially supported by the National Institute for Health Research (NIHR) Biomedical Research Centre based at Guy's and St Thomas' NHS Foundation Trust and King's College London, UK. JSL is funded by the Health Education England (HEE) and NIHR for a PreDoctoral Clinical Academic Fellowship programme. The other authors have no other conflicts of interest to declare.

Ethical Statement: The authors are accountable for all aspects of the work in ensuring that questions related to the accuracy or integrity of any part of the work are appropriately investigated and resolved. This study was conducted in accordance with the Declaration of Helsinki (as revised in 2013) and the Harmonized Tripartite Guideline for Good Clinical Practice from the International Conference on Harmonization. This study is registered as a service evaluation therefore formal ethical approval was not required. However, it was reviewed and approved by the institutional clinical governance review board of Guy's and St Thomas' NHS Foundation trust and registered with a reference number: GSTT-9729. All patients enrolled provided verbal consent.

Open Access Statement: This is an Open Access article distributed in accordance with the Creative Commons Attribution-NonCommercial-NoDerivs 4.0 International License (CC BY-NC-ND 4.0), which permits the noncommercial replication and distribution of the article with the strict proviso that no changes or edits are made and the original work is properly cited (including links to both the formal publication through the relevant DOI and the license). See: https://creativecommons.org/licenses/by-nc-nd/4.0/.

\section{References}

1. Kluger J. What the history of Polio can teach us about COVID-19. Time. 2020 5th May.

2. Halstead LS. Assessment and differential diagnosis for post-polio syndrome. Orthopedics 1991;14:1209-17.

3. Howard RS. Poliomyelitis and the postpolio syndrome. BMJ 2005;330:1314-8. 
4. Lo JK, Robinson LR. Postpolio syndrome and the late effects of poliomyelitis. Part 1. pathogenesis, biomechanical considerations, diagnosis, and investigations. Muscle Nerve 2018;58:751-9.

5. Public Health England. Poliomyelitis and post-polio syndrome: migrant health guide. 2014. Available online: https://www.gov.uk/guidance/poliomyelitis-and-postpolio-syndrome-migrant-health-guide

6. Rogers JP, Chesney E, Oliver D, et al. Psychiatric and neuropsychiatric presentations associated with severe coronavirus infections: a systematic review and metaanalysis with comparison to the COVID-19 pandemic. Lancet Psychiatry 2020;7:611-27.

7. Moldofsky H, Patcai J. Chronic widespread musculoskeletal pain, fatigue, depression and disordered sleep in chronic post-SARS syndrome; a case-controlled study. BMC Neurol 2011;11:37.

8. Lee SH, Shin HS, Park HY, et al. Depression as a Mediator of Chronic Fatigue and Post-Traumatic Stress Symptoms in Middle East Respiratory Syndrome Survivors. Psychiatry Investig 2019;16:59-64.

9. Zwerink M, Brusse-Keizer M, van der Valk PD, et al. Self management for patients with chronic obstructive pulmonary disease. Cochrane Database Syst Rev 2014;2014:CD002990.

10. McCarthy B, Casey D, Devane D, et al. Pulmonary rehabilitation for chronic obstructive pulmonary disease. Cochrane Database Syst Rev 2015;(2):CD003793.

11. Seymour JM, Moore L, Jolley CJ, et al. Outpatient pulmonary rehabilitation following acute exacerbations of COPD. Thorax 2010;65:423-8.

12. Davidson AC, Auyeung V, Luff R, et al. Prolonged benefit in post-polio syndrome from comprehensive rehabilitation: a pilot study. Disabil Rehabil 2009;31:309-17.

13. Larsson Lund M, Lexell J. A positive turning point in life--how persons with late effects of polio experience the influence of an interdisciplinary rehabilitation programme. J Rehabil Med 2010;42:559-65.

14. Kalpakjian CZ, Toussaint LL, Klipp DA, et al. Development and factor analysis of an index of post-polio sequelae. Disabil Rehabil 2005;27:1225-33.

15. Chalder T, Berelowitz G, Pawlikowska T, et al. Development of a fatigue scale. J Psychosom Res 1993;37:147-53.

16. Shmueli A. The Visual Analog rating Scale of healthrelated quality of life: an examination of end-digit preferences. Health Qual Life Outcomes 2005;3:71.

17. Law M, Baptiste S, Carswell A, et al. Canadian
Occupational Performance Measure. 4th edition. CAOT Publications ACE, 2005.

18. Spitzer RL, Kroenke K, Williams JB, et al. A brief measure for assessing generalized anxiety disorder: the GAD-7. Arch Intern Med 2006;166:1092-7.

19. Kroenke K, Spitzer RL, Williams JB. The PHQ-9: validity of a brief depression severity measure. J Gen Intern Med 2001;16:606-13.

20. Perera S, Mody SH, Woodman RC, et al. Meaningful change and responsiveness in common physical performance measures in older adults. J Am Geriatr Soc 2006;54:743-9.

21. Bohannon RW. Comfortable and maximum walking speed of adults aged 20-79 years: reference values and determinants. Age Ageing 1997;26:15-9.

22. Jones CJ, Rikli RE, Beam WC. A 30-s chair-stand test as a measure of lower body strength in community-residing older adults. Res Q Exerc Sport 1999;70:113-9.

23. Murray D, Hardiman O, Meldrum D. Assessment of subjective and motor fatigue in Polio survivors, attending a Postpolio clinic, comparison with healthy controls and an exploration of clinical correlates. Physiother Theory Pract 2014;30:229-35.

24. Tersteeg IM, Koopman FS, Stolwijk-Swüste JM, et al. A 5 -year longitudinal study of fatigue in patients with lateonset sequelae of poliomyelitis. Arch Phys Med Rehabil 2011;92:899-904.

25. Li Hi Shing S, Chipika RH, Finegan E, et al. Post-polio Syndrome: More Than Just a Lower Motor Neuron Disease. Front Neurol 2019;10:773.

26. Lo JK, Robinson LR. Post-polio syndrome and the late effects of poliomyelitis: Part 2. treatment, management, and prognosis. Muscle Nerve 2018;58:760-9.

27. Nordin $\AA$, Taft C, Lundgren-Nilsson $\AA$, et al. Minimal important differences for fatigue patient reported outcome measures-a systematic review. BMC Med Res Methodol 2016;16:62.

28. Kluger BM, Krupp LB, Enoka RM. Fatigue and fatigability in neurologic illnesses: proposal for a unified taxonomy. Neurology 2013;80:409-16.

29. Wan S, Xiang Y, Fang W, et al. Clinical features and treatment of COVID-19 patients in northeast Chongqing. J Med Virol 2020;92:797-806.

30. Williams AC, Eccleston C, Morley S. Psychological therapies for the management of chronic pain (excluding headache) in adults. Cochrane Database Syst Rev 2012;11:CD007407.

31. Festvåg L, Schanke AK, Gilhus NE, et al. Health and 
social conditions in Norwegian polio survivors: A 20-year follow-up study. J Rehabil Med 2016;48:688-95.

32. Foster G, Taylor SJ, Eldridge SE, et al. Self-management education programmes by lay leaders for people with chronic conditions. Cochrane Database Syst Rev 2007;(4):CD005108.

33. Hibbard JH, Stockard J, Mahoney ER, et al. Development of the Patient Activation Measure (PAM): conceptualizing and measuring activation in patients and consumers. Health Serv Res 2004;39:1005-26.

34. Fritz S, Lusardi M. White paper: "walking speed: the sixth vital sign". J Geriatr Phys Ther 2009;32:46-9. Erratum in: J Geriatr Phys Ther 2009;32:110.

35. Abellan van Kan G, Rolland Y, Andrieu S, et al. Gait speed at usual pace as a predictor of adverse outcomes in community-dwelling older people an International Academy on Nutrition and Aging (IANA) Task Force. J

Cite this article as: Curtis A, Lee JS, Kaltsakas G, Auyeung V, Shaw S, Hart N, Steier J. The value of a post-polio syndrome self-management programme. J Thorac Dis 2020;12(Suppl 2):S153-S162. doi: 10.21037/jtd-cus-2020-009
Nutr Health Aging 2009;13:881-9.

36. Stolwijk-Swüste JM, Beelen A, Lankhorst GJ, et al. SF36 physical functioning scale and 2-minute walk test advocated as core qualifiers to evaluate physical functioning in patients with late-onset sequelae of poliomyelitis. J Rehabil Med 2008;40:387-94.

37. Sütçü G, Yalçın A, Ayvat E, et al. Electromyographic activity and kinematics of sit-to-stand in individuals with muscle disease. Neurol Sci 2019;40:2311-8.

38. Turner A, Anderson JK, Wallace LM, et al. An evaluation of a self-management program for patients with long-term conditions. Patient Educ Couns 2015;98:213-9.

39. Atwal A, Spiliotopoulou G, Coleman C, et al. Polio survivors' perceptions of the meaning of quality of life and strategies used to promote participation in everyday activities. Health Expect 2015;18:715-26. 


\section{Statistical analysis}

Descriptive statistics were completed to examine whether there were age and gender differences in the patients whose outcome measures were analysed in the study and the patients with missing data.

A Chi-square test was carried out to review the proportional gender difference between the patients in the analysis of each outcome measure and those who were not included due to missing data. For all outcome measures it was shown that there was no significant gender proportion difference between the two groups (Table S1).

Independent $t$-tests were completed to analyse the age difference of the two groups. Percentage of missing data was also used for the outcome measures when statistical analysis was not appropriate due to the small number of missing data (less than 30). The results showed that there was no age difference between the two groups in terms of quality of life (QoL), 10-m walk test, 2-minute walk test and knowledge test. The analysis showed that patients with missing Canadian Occupational Performance Measure (COPM) data were younger and the difference between the two groups was significant ( $\mathrm{P}$ value $\leq 0.05$ ). The authors reviewed the causes of missing data for this outcome measure. It was noted that a significant number of raw scores were not recorded rather than that the participants did not attend the 6-month follow-up. An attempt was made to retrieve the original documentation but paper notes were no longer available. Percentage of missing data was used for The Index of Post-polio Sequelae (IPPS), Multidimensional Assessment of Fatigue (MAF), Patient Health Questionnaire (PHQ-9), General Anxiety Disorder (GAD-7) and 30sCST as the amount of missing data was too low for statistical analysis. The 30-second Chair Stand test (30sCST) has a high percentage of missing data. However, this outcome measure has only been used with a small number of programme participants and was considered less relevant to the overall conclusions of the study (Table S2).

In conclusion, the descriptive statistics demonstrated that the participants with missing data and those whose data were included in outcomes measures analysis were not different in terms of gender proportion. While age was different between those analysed and those who had missing COPM data, for all other outcomes this difference between groups was not seen. This suggests that the missing data is unlikely to invalidate the overall results.

Table S1 Comparison of gender proportion between the participants whose outcomes measures were included in the study and the participants whose outcomes were missing

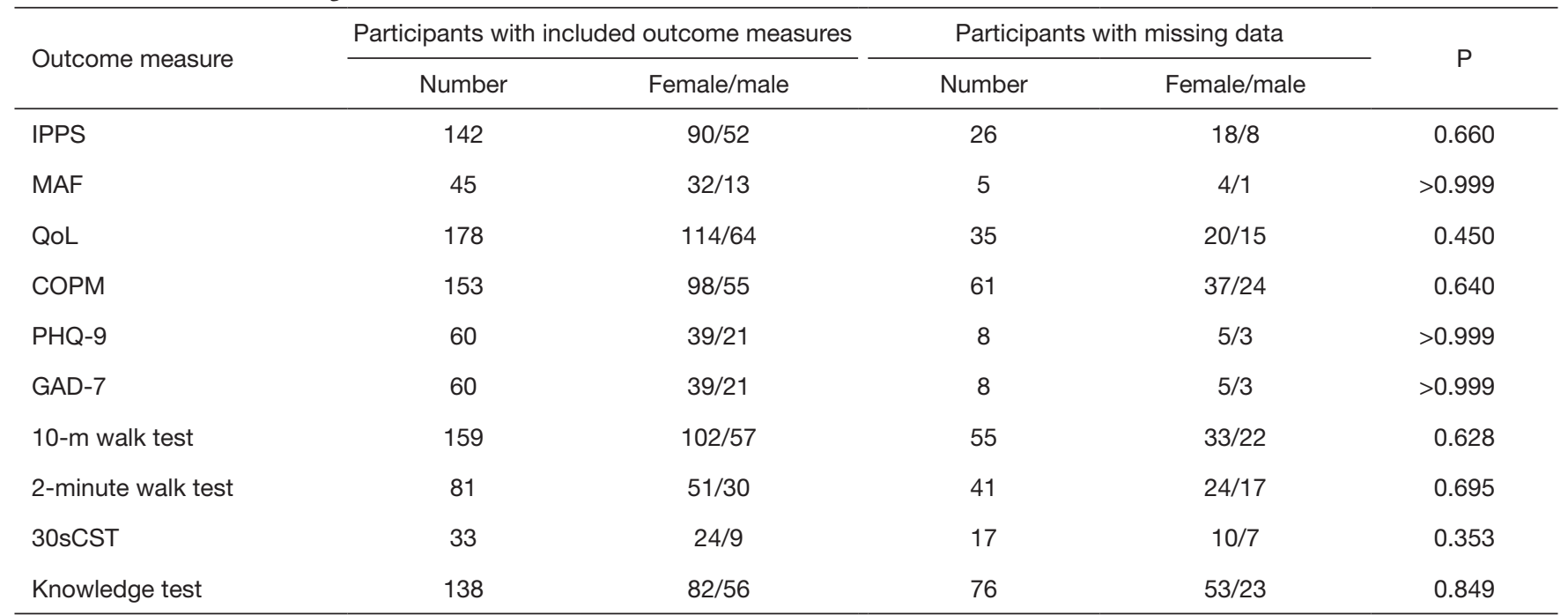

IPPS, The Index of Post-polio Sequelae; MAF, Multidimensional Assessment of Fatigue; QoL, quality of life; COPM, Canadian Occupational Performance Measure; PHQ-9, Patient Health Questionnaire; GAD-7, General Anxiety Disorder; 30sCST, 30-second Chair Stand test. 
Table S2 Comparison of age difference between the participants whose outcome measures were included in the study and the participants whose outcomes were missing

\begin{tabular}{|c|c|c|c|c|c|c|}
\hline Outcome measure & \multicolumn{2}{|c|}{ Participants with included outcome measures } & \multicolumn{2}{|c|}{ Participants with missing data } & $\begin{array}{l}\text { Percentage of } \\
\text { missing data }\end{array}$ & $\mathrm{P}$ \\
\hline IPPS & 142 & $63.4(7.8)$ & $26^{\dagger}$ & $58.4(10.4)$ & $15 \%$ & - \\
\hline MAF & 45 & $65.1(9.6)$ & $5^{\dagger}$ & $49.8(10.5)$ & $10 \%$ & - \\
\hline QoL & 178 & $61.8(8.3)$ & 35 & $59.3(9.0)$ & - & 0.115 \\
\hline PHQ-9 & 60 & $64.8(9.4)$ & $8^{\dagger}$ & $54.9(11.0)$ & $12 \%$ & - \\
\hline GAD-7 & 60 & $64.8(9.4)$ & $8^{\dagger}$ & $54.9(11.0)$ & $12 \%$ & - \\
\hline $10 \mathrm{~m}$ walk speed & 159 & $61.7(8.0)$ & 55 & $60.1(9.6)$ & - & 0.234 \\
\hline 2-minute walk test & 81 & $64.4(7.6)$ & 41 & $61.6(10.0)$ & - & 0.084 \\
\hline
\end{tabular}

${ }^{\dagger}$, outcome measures with less than 30 missing data sets; *, P value $\leq 0.05$. IPPS, The Index of Post-polio Sequelae; MAF, Multidimensional Assessment of Fatigue; QoL, quality of life; COPM, Canadian Occupational Performance Measure; PHQ-9, Patient Health Questionnaire; GAD-7, General Anxiety Disorder; 30sCST, 30-second Chair Stand test. 